for ROP screening on the basis of birth weight and/ or gestational age. Only the first screening examination for each baby was considered. Premature babies, were randomised to one of three interventions before their screening examination: group 1 $(n=27)$ received $24 \%$ sucrose oral, group $2(n=27)$ received $24 \%$ sucrose with pacifier, group $3(n=27)$ received sterile water with pacifier. Pain responses were scored by using the PIPP.

Results A total of 81 infants (42 males and 39 females) were enrolled in the study. The mean birth weight was $1280 \pm 316 \mathrm{~g}$, gestational age was $28.7 \pm 2.1$ weeks and corrected gestational age at examination was $34.2 \pm 2.9$ weeks. The mean PIPP scores in group 1, 2, and 3 were 16.7, 11.4 and 15.1, respectively. Sucrose with pacifier (group 2) had a significantly lower mean PIPP score than group 1 and 3 (p 0.014; 0.021, respectively). Conclusions Sucrose combined with NNS and NNS itself reduce pain scores during screening examinations for ROP.

\section{PS-195 SUCROSE VERSUS BREASTFEEDING FOR VENIPUNCTURE IN TERM INFANTS. A RANDOMISED, PROSPECTIVE, CONTROLLED STUDY WITH ANALYSIS OF THE SPECIFIC CORTICAL RESPONSE}

1J Roué, 'S Rioualen, E Nowak, 'S Roudaut, 'J Sizun. 'Réanimation Néonatale et Pédiatrique, CHRU Brest, Brest, France; ${ }^{2}$ Centre d'Investigation Clinique, CHRU Brest, Brest, France

\subsection{6/archdischild-2014-307384.492}

Background and aims Sucrose and breast milk during painful procedures are reported to decrease pain behavioural expression in neonates. Recent data showed a persistent cortical pain response while using the sucrose during a painful procedure.

To compare the efficacy of sucrose versus breast milk for specific-pain brain activity relief during a painful procedure in neonates.

Methods Randomised, prospective, controlled study. Each term newborn was randomly assigned to sucrose or breastfeeding group at day 3 during a systematic venipuncture. Change in the total haemoglobin concentration in the controlateral somatosensory cortex (Near Infra-red Spectroscoy, NIRS) was assessed 10 seconds before and after the venipuncture. Neonatal Facial Coding System (NFCS) was assessed $2 \mathrm{~min}$ before and at the time of the venipuncture. Groups were compared using Wilcoxon test for the variations in NIRS and Chi-square test for the NFCS scores.

Results 113 newborns were included (sucrose: 56, breastfeeding: 57 ) with a mean (sd) of 39.3 weeks (0.9) for gestational age and $3370 \mathrm{~g} \mathrm{(478)}$ for birth weight. 103 were analysed for the NIRS (sucrose: 55, breastfeeding: 48). Median (quartiles) of total haemoglobin concentration change was $-8.5 \mu \mathrm{mol} / \mathrm{L}(-34.5 ; 12.5)$ for sucrose group and $12.3 \mu \mathrm{mol} / \mathrm{L}(-23.4 ; 39.3)$ for breastfeeding group with no statistical difference $(\mathrm{p}=0.06)$. NFCS scores were significantly different with $46.8 \%$ with a painful score in the breastfeeding versus $26.8 \%$ in the sucrose ( $p=0.03$ ).

Conclusions No difference were found between sucrose and breastfeeding on specific-pain brain activity during a venipuncture in term newborns. A discordance was revealed between NFCS scores and NIRS analysis.

\section{PS-196 WITHDRAWN}

\section{PS-197 A RANDOMISED TRIAL OF ESTIMATING UMBILICAL CATHETER INSERTION DEPTH IN NEWBORNS USING BIRTH WEIGHT OR SURFACE MEASUREMENTS (ISRCTN17864069)}

E Kieran, E Laffan, C O'Donnell. Neonatology, The National Maternity Hospital, Dublin, Ireland

\subsection{6/archdischild-2014-307384.493}

Background Incorrect umbilical venous and arterial catheter (UAC and UVCs) tip position is associated with increased rate of complications.

Objective To determine whether using birth-weight (BW), rather than body surface measurement (M), to estimate ID of UVC and UACs results in more correctly placed catheters.

Methods Newborns undergoing UVC and/or UAC insertion were randomised to have ID estimated using BW [UVC: $\mathrm{cm}=$ $(\mathrm{BW} \times 1.5)+5$; UAC: $\mathrm{cm}=(\mathrm{BW} \times 3)+9]$ or using shoulder to umbilicus measurement (M). The primary outcome was correct catheter tip position on X-ray (UVC T9-T10; UAC T6-T10).

Results We enrolled 101 newborns. UVC insertion was successful in 97 (96\%). There was no difference in correctly placed UVCs between groups (Table). UAC insertion was attempted in 87 infants and was successful in $62(71 \%)$. More infants in the W group had a catheter tip in the correct position (Table). We found no differences in secondary outcomes.

\begin{tabular}{|c|c|c|}
\hline UVC & Weight $(\mathrm{N}=53)$ & Weight $(\mathrm{N}=53)$ \\
\hline T9-T10 n (\%) & $16 / 51(31)$ & $13 / 46(28)$ \\
\hline Too high $(<T 9)^{\#}$ & $11 / 51(22)$ & $5 / 46(11)$ \\
\hline Too low $(>T 10)^{\#}$ & $10 / 51(20)$ & $20 / 46(43)$ \\
\hline UAC & Weight $(N=46)$ & Measure $(\mathrm{N}=41)$ \\
\hline T6-T10\# & 29/32 (91) & $15 / 30(50)$ \\
\hline Too high $(<T 6)^{\#}$ & 3/32 (9) & $0 / 30(0)$ \\
\hline Too low $(<\mathrm{T} 10)^{\#}$ & $0 / 32(0)$ & $15 / 30(50)$ \\
\hline
\end{tabular}

Conclusions UVCs often cannot be advanced to the estimated ID or are in the portal venous system on X-ray. Estimating UVC ID using BW did not result in more correctly placed UVCs. When successful, estimating UAC ID using BW results in more correctly placed catheters.

\section{PS-198 TOPICAL GLYCERYL TRINITRATE OINTMENT TO AID UMBILICAL ARTERY CANNULATION IN NEONATES}

AR Rafferty, M Thio, L McGrory, C Theda, PG Davis. Newborn Research Centre, The Royal Women's Hospital, Melbourne, Australia

\subsection{6/archdischild-2014-307384.494}

Background and aims Umbilical artery cannulation is a common neonatal procedure that is often challenging because umbilical arteries constrict after birth. We aimed to determine whether the topical application of a vasodilating ointment prior to cannulation increases success and decreases the time taken to cannulate. Methods Discarded umbilical cords were collected immediately after delivery and two $3 \mathrm{~cm}$ sections proximal to the baby were used for the study. $0.1 \mathrm{~mL}$ topical Glyceryl Trinitrate (GTN) ointment $(0.2 \% \mathrm{w} / \mathrm{w})$ was applied to the surface of one section for 5 min prior to cannulation, whereas the second section acted as the control. After ointment removal, medical staff blinded to intervention attempted to cannulate one artery in each section. 